University of Massachusetts Amherst

ScholarWorks@UMass Amherst

2009

\title{
Successful features: Verb raising and adverbs in L2 acquisition under an Organic Grammar approach
}

Anne Marjatta Vainikka

University of Massachusetts Amherst

Follow this and additional works at: https://scholarworks.umass.edu/av_workssite_acquisition

Part of the First and Second Language Acquisition Commons

Vainikka, Anne Marjatta, "Successful features: Verb raising and adverbs in L2 acquisition under an Organic Grammar approach" (2009). Language Acquisition Work by Anne Vainikka. 10.

Retrieved from https://scholarworks.umass.edu/av_workssite_acquisition/10

This Article is brought to you for free and open access by the Anne Vainikka Works Site at ScholarWorks@UMass

Amherst. It has been accepted for inclusion in Language Acquisition Work by Anne Vainikka by an authorized administrator of ScholarWorks@UMass Amherst. For more information, please contact

scholarworks@library.umass.edu. 


\title{
Successful features
}

\section{Verb raising and adverbs in L2 acquisition under an Organic Grammar approach}

\author{
Anne Vainikka and Martha Young-Scholten \\ Johns Hopkins University and Newcastle University
}

\begin{abstract}
Under Organic Grammar (Vainikka and Young-Scholten 2005; 2007), the building of L2 syntactic structure is constrained by UG in interaction with primary linguistic data. On the basis of verb raising, we argue against the partial UG availability pursued in Hawkins and Chan (1997) in their Failed Functional Features Hypothesis, whose refinement by Hawkins and Hattori (2006) states that only those uninterpretable syntactic features present in the learner's L1 remain accessible for L2 acquisition. After summarizing UG-driven L2 German verb raising, we consider French/English adverb placement data pointing to L1-driven verb raising (White, 1991a, b; Schwartz, 1996). However, absence of Frenchlike raising in questions and negation (White 1992; Eubank 1994) requires an alternative account. Based on Vainikka's (2007) framework which dispenses with Cinque's (1999) prolific projections, we provide an alternative analysis.
\end{abstract}

\section{Introduction}

If Universal Grammar (UG) is fully available throughout the lifespan, why do we routinely observe the systematic failure of post-puberty learners to attain nativelike morpho-syntactic competence in a second language? Unlike the Fundamental Difference Hypothesis (Bley-Vroman 1990; Clahsen and Muysken 1986), hypotheses such as Minimal Trees/Structure Building (Vainikka and Young-Scholten 1994) and Full Transfer/Full Access (Schwartz and Sprouse 1996) assume complete and direct access to UG by younger and older learners alike. However, Hawkins and Chan (1997) have contested the view that UG is available in toto. Unlike some proponents of the Fundamental Difference Hypothesis, for example Clahsen and Muysken (1986), Hawkins and Chan take the position that second language grammars are UG-constrained, while nonetheless arguing that UG is only partially available to adults. For the latter, partial availability revolves around 
the idea that after the end of the critical period, certain subparts of UG start to become less accessible or are completely inaccessible. The hypothesis Hawkins and Chan put forward, Failed Functional Features, refers to the idea of a Representational Deficit (Hawkins 2005), which has since been further refined as a hypothesis that rules out the learner's access to uninterpretable, syntactic features in the L2 which are not present in the L1 (e.g., Hawkins and Hattori 2006; Tsimpli and Dimitrakopoulou 2007).

Unlike Full Transfer/Full Access proponents such as Schwartz and Sprouse (1996), Hawkins (2001) pursues the idea that the L2 learner gradually builds up syntactic structure from an initial point at which there are only lexical projections. That is, the L2 learner's initial state in L2 acquisition is not equivalent to the learner's entire knowledge of the L1. For Hawkins, during development, syntactic projections can then be modulated by the learner's L1. Under the Failed Functional Features Hypothesis modulation entails the L2 learner only being able only to posit those functional projections that draw on features existing in the learner's L1. We return to this point below.

\section{Verb raising and the minimal trees and structure building of Organic Grammar}

We argue that not all functional features are equal; consider verb raising. In a new paper that draws on comprehension data from Arabic, Chinese, French, German, Japanese and Spanish speakers of English Hawkins et al. (2008) conclude that the systematic differences found between the main verb raising in L1 group (Arabic, French, German and Spanish speakers) and the non-raising in L1 group (Chinese and Japanese) point to adult L2 learners' failure to access uninterpretable features not represented in their L1s. Hawkins et al. assume verb raising involves narrow syntax and they adopt Adger's (2003) Minimalist account under which the agree operation involves the interaction between the interpretable features present, past and progressive and the uninterpretable feature INFL.

Like Hawkins et al. we assume verb raising is syntactic. But we part ways in terms of evidence for application of non-L1 uninterpretable features. There is ample evidence of the successful acquisition of verb raising, where data from studies of learners' production have shown that, regardless of the learner's age upon L2 exposure, non-L1-based verb raising is acquired (e.g., Vainikka and Young-Scholten 1994; 2002). Data from adult English, Korean, and Turkish learners of German suggest that the Failed Functional Features/Representational Deficit hypotheses are too strong. In the three L1s in question, thematic verb raising either does not exist (English) or all lexical and functional projections are head final (Korean and 
Turkish). These data, as well as the data from speakers of Italian and Spanish in whose L1s thematic verb raising does occur, point to a non-L1-based, common pattern of acquisition for all L2 German learners. In one particularly crucial respect, the pattern is similar to that of children learning German as their first language: the first functional projection is of an underspecified head-initial functional projection, eventually followed by the adult/target head-final German AgrP.

Under what is now referred to as Organic Grammar (Vainikka \& YoungScholten 2005; 2007), ${ }^{1}$ all language learners at the earliest stages of acquisition project only a Minimal Tree, i.e., only lexical categories such as VP. Learners at the initial state rely exclusively on such a projection. For beginning L2 learners, these lexical projections are L1-based as shown in (1) where a Korean learner produces a head-final Korean VP, and in (2) where an English learner produces a head-initial English VP (data from Vainikka \& Young-Scholten 1994; 2007).

(1) Eine Katze Fisch alle essen.

(Changsu/Korean L1)

a cat fish all eat-INF

[Eine Katze hat den ganzen Fisch gefressen.]

'A cat ate the whole fish.'

(2) Peter lernen die Buch.

Peter learn-INF the book.

(Paul/English L1, month 2)

[Peter liest das Buch.]

'Peter reads the book.'

If and when the L2 learner receives sufficient target language input, the next step in his/her syntax is a target-language-based Minimal Tree, as shown in (3), where Salvatore has switched his previously head-initial VP to a head-final one (see Vainikka and Young-Scholten 1996b).

(3) Vielleicht Schule essen.

Salvatore, Session 6

(L1 Italian)

maybe school eat-INF

[Vielleicht isst sie in der Schule.]

'Maybe she eats at school.'

At the early stages, as exemplified by the data in (1) - (3), functional projections are absent, but the interaction of primary linguistic data with UG enables the learner to progress further to build functional structure that begins to resemble

1. Introduction of the term Organic Grammar stems from the need to arrest the terminological confusion about Structure Building, and to encompass both the Structure Building and the Economy (under Minimalism) aspects of this approach. The new term is also a response to variable and often incorrect use of terms such as "Minimal Trees/Structure Building" and "Weak Continuity Hypothesis" applied to our approach. 
that of the target language. For German this involves raising the thematic verb to second position in declaratives, and to final position (due to a head-final AgrP) in embedded clauses. Learners in an input-rich environment from the start of initial exposure reach this final stage, as in the case of the American secondary school exchange student, Joan, who like the many of the immigrants studied, had had no prior exposure to German upon arrival in that country and received no regular instruction in German once there (see Vainikka and Young-Scholten 2002). Apart from a case error with im in her twelfth month in Germany Joan's morpho-syntax is completely German.

(4) Und ich habe mit Markus geredet, so weil Kosta schon ins Bett war. and I have with M. spoken, so because K. already into bed was [Und ich habe mit Markus geredet, weil Kosta schon im Bett war.]

'And I spoke with Markus because Kosta was already in bed.'

Unlike under Hawkins' (2001) Modulated Structure Building, within an Organic Grammar framework, there is no recourse by the learner to the L1 during the acquisition of functional syntax. With structure building constrained only by UG, no differences for a given L2 are expected for learners from languages which differ in terms of functional features. In the L1 English/L2 German data one might, for example, expect to see evidence that the value of auxiliary 'be' or 'have' transfers from English to German, since equivalent auxiliaries (sein and haben) with similar functions exist. Thematic verb raising, since it does not occur in English, should proceed more slowly than for, say, Spanish and Italian learners of German. There is no evidence of either sort of influence in the data, and indeed no other differences have been found across native languages in the adult L2 German data.

At the stage of development immediately following the bare VP, learners of German - the L1 children as well as the L2 adults we have studied - project an underspecified head-initial functional projection to which they optionally raise verbs. This is shown in (5), where the Turkish native speaker Sevinc adds to his interlanguage German new syntactic structure which is not present in strictly head-final Turkish (see Vainikka and Young-Scholten 1994).

(5) Jetzt brau Wohnungsamt fragen.

(Sevinc/Turkish L1)

now need-0/1SG housing.authority ask-INF

[Jetzt brauche ich das Wohnungsamt fragen.]

'Now (I) need to ask (the) housing authority'

At the earliest stages of the acquisition of German, all learners produce non-finite verb forms when the verb has not raised, pointing to a common Optional Infinitive Stage (Wexler 1994) in German at which Root Infinitives dominate, i.e., syntactic structure is truncated (Rizzi (1993/4). Joan's production of thematic verbs in 
default $(-n)$ form is typical of the prevalence of such forms in the early L2 German data. In the first two samples (her second and third month in Germany) when she has only projected her head-initial English-based bare VP, of the 47 thematic verbs she produces, 25 end in $-n$ and a further 11 in $-e$ or no suffix and are incorrect with respect to the intended person and number.

(6) Ich trinken Tee immer morgen.

I drink tea always morning

(Joan/L1 English)

[Ich trinke morgens immer Tee.]

'I always drink tea in the morning.'

Adult L2 learners differ, however, from child L1 learners, and appear to differ as well from child L2 learners, in terms of their production of default forms in raised positions of the sort shown in (7) and (8). While learners such as Joan may hardly evidence default forms in raised positions due to the rapidity of their development, for those second language learners in acquisition- poor environments, use of default forms persists in the context of stalled syntactic development.

(7) Und dann nachher kommen die Sonne nochmal wieder.

[Und dann nachher kommt die Sonne nochmal wieder.]

(Maria/L1 Spanish)

again

'And then afterwards the sun comes out again'

(8) Ich sehen Schleier.

(Kemal/L1 Turkish)

I see-INF veil

[Ich sehe den Schleier.]

'I see the veil'

The default form data point to a deficit not captured by Hawkins and Chan's (1997) FFFH. The deficit responsible might relate to surface morphology, as discussed in Prévost and White (2000a, b, c). Alternatively, the deficit might derive from the prosodic constraints of the learner's L1 phonology, as pursued in Goad, White and Steele (2003). And the deficit could well be a combined one (see e.g., Bayley 1996). For now, however, we leave further consideration of the source of such non-target morphological patterns aside (but see also Vainikka and Young-Scholten (1998; 2007) on the interface of phonology, morphology and syntax under Organic Grammar). 


\section{Verb raising across languages: the case of French learners of English}

On the basis of the German data, we conclude that L1 verb raising and what verb raising entails does not transfer in L2 acquisition. However, there is a set of problematic data that points to L1 influence. Dating back to White (1991a/b), it has been argued that the position of finite thematic verbs in data from French learners of English reveals the systematic allowance of non-target utterances such as in (9), which indicate erroneous, L1-based raising of thematic verbs, vs. target-languageconforming auxiliary placement, as in (10). In other words, French verb raising transfers. (see Hawkins, Towell and Bazergui's (1993) analysis of this as a problem with Agr in the L2, based on systematic differences between English learners of French and French learners of English.)

(9) ${ }^{\star}$ John reads frequently linguistics books.

(10) John is frequently reading linguistics books when the library closes.

In French, but not in English, the thematic verb is raised to a functional head (see e.g., Emonds 1978; Pollock 1989). Thus the errors found in learners' L2 English could be explained by assuming that the French speakers have transferred from their L1 the information that verbs raise, contrary to the English input. If only a VP were transferred from French to English, as claimed under Organic Grammar, how could information about raising to a functional projection be transferred? The French data sit well under an approach such as Schwartz and Sprouse's (1996) Full Transfer/Full Access Hypothesis. They also support the Failed Functional Features Hypothesis; an account for these data involves precisely the sort of uninterpretable features that guide L2 acquisition: those that are L1-based.

The data under consideration here seem to constitute a problem for Organic Grammar, which ascribes neither failure nor success to L1 influence. Yet if we look a bit more closely at previous analyses, we find that the basis on which transfer of verb raising is argued to occur is shaky. While White's (1991a, b) and Schwartz's (1996) analyses of the data are based purely on the adverb context shown in (9), the full L2 English data reveal that French-like verb raising does not occur in questions or in negation, as pointed out in White (1992). ${ }^{2}$ Other, longitudinal data indicate there is no stage for French learners of English where French-type verb raising occurs, as detailed in Eubank (1994) in reference to studies by Gerbault

2. Interestingly, the reverse situation does not seem to hold, if L1 verb raising facts are transferred. The English speakers acquiring French studied by Grondin and White (1993) raised main verbs to INFL, prompting the authors to conclude that they used "the functional projections in their grammars in ways that are appropriate to the L2, rather than in ways that are appropriate to the L1." (1993:143). 
(1978) and Tiphine (1983). And finally, Ayoun's (2005) study indicates that adult French-speaking learners of English cease misplacing adverbs at more advanced stages of acquisition.

\section{Adverbs and syntactic projections}

How, then, do we explain the placement of adverbs in French-English interlanguage?

These interlanguage data can be demystified by adopting the three assumptions shown in (11):

(11) a. Adverbs occur in a number of specifier positions (rather than adjoined) in various locations in the syntactic tree.

b. Adverbs are a lexical category. L1-based patterns in the interlanguage data are evidence for lexical transfer, in line with Organic Grammar.

c. Functional projections need to be filled by syntactic material. Absence of material in the head position may result in verb raising.

These assumptions point to the appearance of verb raising in declaratives and explain its non-occurrence with negation and in questions. Let us expand on these three points by looking at previous accounts of adverb position.

In his drastic departure from the traditional analysis of adverbs, Cinque (1999) argues that rather than being adjoined to the VP as under traditional approaches, adverbs (in Italian) occur in a number of specifier positions in various locations of the syntactic tree. Under Cinque's approach, adverbs are no longer strictly speaking adjuncts but occupy non-adjoined positions. The impetus for this analysis comes from Kayne's (1994) proposal to restrict adjunction in general. Alexiadou (1997) and Laenzlinger (1998) also apply Kayne's idea to adverbs (in Greek and French), suggesting that adverbs occupy specifier positions. In order to explain certain word order and scope patterns, Cinque proposes that each adverb is basegenerated in a separate functional projection. However, there are major problems with his approach. First, there is often no other evidence for the projection other than the adverb. Second, such an analysis of adverbs requires an unconstrained approach to functional projections, and by the end of his 1999 book, Cinque has posited over 30 functional projections universally for straightforward declarative clauses alone. He then comments that even more projections are likely to emerge in the theory as more data are considered. While theorizing is possible within the confines of formal linguistics, at some point, the proposed structure must be accountable to acquisition. 
The child would start off with a great Ur-baobab tree which covers all possibilities in all languages, and this is how the tree would remain (under the Strong Continuity view this entails; see e.g., Boser, Lust, Santelmann and Whitman, 1992; Hyams, 1992; Poeppel and Wexler, 1993; Weissenborn, 1990). We argue that such a story is untenable. If every child is born with myriad projections, evidence must exist in the primary linguistic data for the realization only of subsets of these adverbial projections in a given language, i.e., for the establishment of a specific grammar. It can be argued that, given what we know about the general uniformity coupled with parsimony with which children undertake the task of language learning, children do not operate with such congenitally dense trees.

\subsection{A reanalysis of adverbs and a reanalysis of the L2 French data}

In the first application of Organic Grammar to syntax, Vainikka (2007) presents a new analysis of adverbs, using English as a starting point. This approach is related to Cinque's, to Alexiadou's and to Laenzlinger's in that adjunction is curtailed, with adverbs instead occupying specifier positions. Vainikka's analysis goes the required step further in its adoption of an Organic-Grammar approach to functional projections based on acquisition, resulting in roughly 10 functional projections in the most complex sentences. Sentences and languages vary in exactly which projections are posited, and under this approach, adverbs typically occur either in the VP, or are raised to specifier positions of (existing) functional projections. Importantly, the strong association between the semantics of a particular adverb and its projection that Cinque posits is no longer necessary and not maintained in Vainikka's approach.

Schwartz (1996) claims the French-English adverb data provide compelling evidence against the structure building component of Organic Grammar (Schwartz 1996), but there are important ramifications of an Organic Syntax-based adverb analysis for these classical L2 acquisition data. Schwartz presents the following putative counterargument to structure building. The Structure Building Hypothesis predicts that verb raising (or any other type of raising involving a functional projection) would not be transferred under L2 acquisition, since the hypothesis entails that functional projections are not transferred, but projected solely through the interaction of UG with the primary linguistic data. Under Schwartz and Sprouse's (1996) Full Transfer/Full Access Hypothesis, functional syntax is transferred along with verb raising during L2 acquisition; evidence of this is the position of adverbs in the French-English data. The flipside of the Failed Functional Features coin similarly predicts transfer; those features present in the learner's L1 are not only accessible but also accessed during L2 acquisition. The former (accessible) implies success, but of course when the L1 and L2 differ, as in the case of 
French and English the latter (accessed) results not in success, but also in failure, i.e., in non-target like structure.

Arguing on the basis of the data in White's (1991a, b; 1992) study, Schwartz points out that French learners of English tend to allow sentences in which the thematic verb appears to have been raised, as in the L1 French (but not in English, see e.g., Emonds 1978, Pollock 1989). White's data show that verb raising sometimes occurs in the learners' L2 English when the sentence contains an adverb such as frequently; that is, the finite verb precedes the adverb as in the L1 French (but not in the target language, as in example (9) repeated here as (12).

(12) ${ }^{\star}$ John reads frequently linguistics books.

In allowing such constructions, it appears that the French-speaking L2 English learners studied are raising the verb from the VP to a position higher in the tree, preceding the adverb. But as pointed out above, there are problems with this analysis. The obvious solution to explain these data - and, as also noted above, the one invariably entertained - is that verb raising transfers from the L1 to the L2. Yet verb raising appears to occur only in the data in the adverb context, contrary to native French. Indeed White (1992) shows that French-based verb raising does not occur in questions or negation in French-English interlanguage, as would be expected if French-type verb raising were operative. ${ }^{3}$ Here White (1992) admits that apparent 'verb raising' in the adverb data could be due to a different process, if Iatridou (1991) is correct in claiming that adverb placement differs across languages. Bolstering the position that the accepted analysis is actually incorrect, we refer to Eubank (1994), who points out that there is no stage with French-type verb raising in the longitudinal L2 English (L1 French) data from Gerbault (1978) and Tiphine (1983). ${ }^{4}$ Evidence of transfer of verb raising thus rests solely on adverb position, and it is important to consider whether the new developments in adverb analysis described above undermine the original argument.

\subsection{Reassessing the verb raising argument: Applying Organic Syntax}

While Cinque wishes to argue that adverb position is universally uniform, if we take an Organic Syntax approach, the immediate result is considerably more

3. Given the lack of verb raising in question or negation contexts, our argument against Schwartz (1996) in Vainikka and Young-Scholten (1996a) does not hold. There we suggested that based on the distribution of auxiliaries in the L2 English input, the learner might posit verb raising. However, if that were the case, we would expect to find verb raising also in question and negation contexts.

4. Note that Håkansson (2001) and Sayehli (2001) claim that verb raising does not transfer from L1 Swedish to L2 German, although both languages have verb raising. 
flexibility. Under Organic Grammar, there is a language-specific Master Tree whereby the set of specific functional projections varies across languages. In Vainikka and Young-Scholten (2007), ten assumptions underlying this notion are introduced. The first seven assumptions define the backbone of syntactic structure, the Master Tree, while the last three deal with related issues. Central to these assumptions is the idea that there is no fixed universal CP tree that contains all possible functional projections. Cross-categorial generalizations can be stated in the grammar based on the Master Tree, as under Kayne (1994), but unlike Kayne, there is no assumption of common (initial) headedness across languages. The second assumption captures the essence of structure building. Here we draw on Baker's (1985) Mirror Principle, where inflectional morphology mirrors syntax, in particular, functional projections. Cross-linguistic differences in projections and in their headedness (contra Kayne 1994) are thus allowed. We also follow those who limit functional projections to those which are warranted, i.e., Fukui and Sakai (2003), Giorgio and Pianesi (1997), Grimshaw (1997), and particularly Speas (2001), on Economy of Projection.

Assumption 1: Each language has a Master Tree that includes all possible projections occurring in the language.

Assumption 2: All and only those projections occur in the Master Tree for which there is evidence in the language.

Assumption 3: Universal Grammar provides the tools for acquiring the Master Tree, based on input.

Assumption 4: The Master Tree is acquired from the bottom up.

Assumption 5: The Acquisition-Syntax Correspondence: syntax mirrors acquisition.

Assumption 6: Actual instantiations of the tree are projected from the bottom up, based on the Master Tree.

Assumption 7: Partial trees may be projected for constructions which do not involve the full Master Tree structure.

Assumption 8: Lexical and functional projections differ in terms of how they are represented in the grammar.

Assumption 9: Cross-categorial generalizations about structure are possible.

Assumption 10: Only as much adjunction is posited as necessary.

Assumptions 3, 4 and 5 are relevant to our discussion of acquisition in general. Rather than invoke any language-external influence (such as processing as in 
Processability; see Vainikka and Young-Scholten 2005) on morpho-syntactic development, it is the syntax itself that drives acquisition.

With respect to adverbs, these assumptions a priori rule out an approach such as Cinque's. First, the idea of economy rules out the proliferation of scores of projections in a given language. Second, the prospect of language-specific syntax structures (i.e., Master Trees) obviates the need for including all syntactic possibilities. And finally, assumption 10 notes the undesirability of adding adjoined projections. In the spirit of Emonds' (1985) Structure Preserving Hypothesis, the Master Tree excludes adjoined projections as these are costly for the grammar to posit.

\subsection{Adverbs in Organic Syntax}

Under Organic Syntax, adverbs do not occur in adjoined positions, but rather in various specifier positions, depending on the availability of each position. The approach to adverbs introduced here makes it completely plausible to suggest, following Iatridou's (1991) original proposal, that there is cross-linguistic variation in terms of the specific adverbs that occur in each specifier position. However, it turns out that given Vainikka's (2007) analysis, the adverb diagnostic for verb raising still holds for certain adverbs. The most reliable class of adverbs for this diagnostic are those adverbs that may raise out of the $\mathrm{VP},{ }^{5}$ but that cannot raise any higher than the Spec(TP) position. Sentential adverbs, in particular, may occupy positions high in the tree, and such adverbs then precede the verb regardless of whether it remains in the VP or is raised to a functional head such as Agr or T. Adverbs that can be used as a diagnostic are (under Vainikka 2007) Class II adverbs of degree and manner - such as completely or easily - as well as Class III adverbs of time or frequency such as frequently or often, as used in White's study.

Given the idea of a Master Tree, we can posit that the adverb frequently and its French counterpart occupy different syntactic positions. This is an option available under Organic Grammar. Since adverbs are a lexical category (being an open class derivable from the lexical class of adjectives), rather than a functional one, the adverb itself would carry information about its syntactic position, and this lexical information can transfer under an approach such as ours that allows the transfer of lexical, but not functional features. This sort of account would also explain why French learners of English do not raise verbs in their L2 English with negative or

5. Class I adverbs - short adverbs such as well and fast - cannot be raised out of the VP and therefore will not work as a diagnostic for verb raising since the verb would precede the adverb whether raised or not (see Vainikka 2007). While the analysis of the short adverbs is straightforward, it currently remains unclear why they cannot raise. 
interrogative constructions. As we note above, this would be expected if Frenchtype verb raising were indeed transferred.

Having suggested this as a possible scenario, we must rule it out. We do not think this is a fruitful approach; it is highly unlikely that two closely related languages such as English and French would differ in terms of regular adverb placement. Thus, despite the new developments in the theory of adverbs, the central problem therefore remains: what is the syntactic analysis of ${ }^{\star} J o h n$ reads frequently linguistics books in French speakers' L2 English? We think that the answer lies in a theory of movement currently under further development: the Full House Principle (FHP).

\subsection{The Full House Principle}

According to this principle, there is a tendency on the learner's part to fill an empty syntactic position by moving an element to it. The earliest version of the idea that syntactic positions need to be filled - preferably with overt material - is from Vainikka and Young-Scholten (1994); see also Vainikka and Levy's 1999 POOL, Principle of Obligatory Occupant Licensing, which is useful in accounting for the patterns of empty subjects in Finnish and Hebrew. The FHP was proposed to account for movement into a functional projection without syntactic features (the FP), evident in data from learners who in their acquisition had moved beyond their projection of a bare VP. Consider a typical situation during the L2 acquisition of English where a TP (or FP, as in previous publications by Vainikka and YoungScholten) has been projected, but an AgrP projection has not yet been posited. If the speaker - perhaps based on an overt element in the specifier position - somewhat prematurely posits an AgrP position without having yet acquired the full agreement paradigm, the grammar would attempt to fill that empty (i.e., devoid of features) Agr position by moving a verb from below into it, regardless of whether the L1 or the $\mathrm{L} 2$ have verb raising. That is, verb raising would be a readily available option in UG that would surface especially during acquisition prior to the acquisition of the appropriate morphology. Example (5), repeated here as (13), illustrates this, where the adverb jetzt 'now' fills an empty position rather than the required subject.

Jetzt brau Wohnungsamt fragen.
now need-0/1SG housing.authority ask-INF
[Jetzt brauche ich das Wohnungsamt fragen.]
'Now (I) need to ask (the) housing authority'

Returning to English, once the agreement morphology has been acquired, the learner is in a position to also acquire the universally exceptional feature lowering of English (from Agr and T to the non-raised main verb). With respect to White's data, an experimental situation (a grammaticality judgment task) such as hers may 
be particularly likely to involve positing of projections that learners have not yet fully acquired, thus resulting in filling an empty higher position by verb movement. In negative sentences, negative morphology would occupy NegP, and verb raising would not be required to fill a head position, and similarly for question morphology and the $\mathrm{CP}$ projection. Thus, rather than providing evidence for transfer of verb raising, White's data may provide evidence for a stage at which all functional projections have not yet been acquired.

\section{Conclusion: Ramifications for the Failed Functional Features Hypothesis}

If, as under the Failed Functional Features Hypothesis, uninterpretable features not present in the learner's L1 cannot be activated by adult second language learners, it will matter whether verb raising is always driven by such features (as assumed under Minimalism, Chomsky 1995), or whether there is a mechanism such as the Full House Principle, whereby an element may raise in order to fill a syntactic position. If verb raising during L2 acquisition is motivated by a lack of features/ phonological material in a functional projection, then - despite any possible nonacquisition of uninterpretable features - verb raising could nonetheless occur during the development of a second language. If, however, such features are required in order for verb raising to take place, the FFFH would predict that no non-L1type verb raising should be found during adult second language acquisition. White's original data would then also present a problem for the FFFH, since it cannot be shown that the adverb examples in L2 English involve French-type verb raising, given the lack of such raising in negative sentences and questions.

While we remain agnostic about a critical period for uninterpretable features which results in the impossibility of acquiring such features during adult L2 acquisition, our solution to the adverb dilemma allows (non-L1) verb raising to occur during L2 acquisition, even assuming the Failed Functional Features Hypothesis.

\section{References}

Adger, D. 2003. Core syntax. A minimalist approach. Oxford: OUP.

Alexiadou, A. 1997. Adverb placement. A case study in antisymmetric syntax. Amsterdam: John Benjamins.

Ayoun, D. 2005. Verb movement in the L2 acquisition of English by adult native speakers of French. In Eurosla Yearbook 5, S. H. Foster-Cohen, M. del Pilar Garcia-Mayo \& J. Cenoz (eds), 35-76. Amsterdam: John Benjamins. 
Baker, M. 1985. Incorporation: A theory of grammatical function changing. PhD dissertation, MIT.

Bayley, R. 1996. Competing constraints on the variation of the speech of adult Chinese learners of English. In Second language acquisition and linguistic variation, R. Bayley \& D. R. Preston (eds), 97-120. Amsterdam: John Benjamins.

Bley-Vroman, R. (1990) The logical problem of foreign language learning. Linguistic Analysis 20: 3-49.

Boser, K., Lust, B. Santelmann, L. \& Whitman, J. 1992. The syntax of CP and V-2 in early child German (ECG): The Strong Continuity Hypothesis. In Proceedings of NELS 23, K. Broderick (ed.), 51-65. Amherst MA: GLSA.

Chomsky, N. 1995. The minimalist program. Cambridge MA: The MIT Press.

Cinque, G. 1999. Adverbs and functional heads: A cross-linguistic perspective. Oxford: OUP.

Clahsen, H. \& Muysken, P. 1986. The availability of universal grammar to adult and c h i l d learners: A study of the acquisition of German word order. Second Language Research 2: 93-119.

Emonds, J. 1978. The verbal complex V'-V in French. Linguistic Inquiry 9: 151-175.

Emonds, J. 1985. A unified theory of syntactic categories. Dordrecht: Foris.

Eubank, L. 1994. On the transfer of parametric values in L2 development. Language Acquisition 3: 183-208.

Fukui, N. \& Sakai, H. 2003. The visibility guideline for functional categories: Verb raising in Japanese and related issues. Lingua 113: 321-375.

Gerbault, J. 1978. The acquisition of English by a five-year-old French speaker. MA thesis, UCLA.

Giorgio, A. \& Pianesi, F. 1997. Tense and aspect. From semantics to morphosyntax. Oxford: OUP.

Goad, H., White, L. \& Steele, J. 2003. Missing inflection in L2 acquisition. Defective syntax or L1-constrained prosodic representations? Canadian Journal of Linguistics 48: 243-263.

Grimshaw, J. 1997. Projection heads and optimality. Linguistic Inquiry 28: 373-422.

Grondin, N. \& White, L. 1993. Functional categories in child L2 acquisition of French. McGill Working Papers in Linguistics, 121-145.

Håkansson, G. 2001. Against full transfer: Evidence from Swedish learners of German. Lund University Department of Linguistics Working Papers 48: 67-86.

Hawkins, R., Towell, R. \& Bazergui, N. 1993. Universal Grammar and the acquisition of French verb movement by native speakers. Second Language Research 9: 189-233.

Hawkins, R. 2001. Second language syntax: A generative introduction. Oxford: Blackwell.

Hawkins, R. 2005. Revisiting wh-movement: The availability of an uninterpretable [wh] feature in interlanguage grammars. In Proceedings of the 27th Generative Approaches to Second Language Acquisition Conference, B. Beachley, A. Brown \& F. Conlin (eds.), 124-137. Somerville MA: Cascadilla Press.

Hawkins, R. \& Chan, C. Y-H. 1997. The partial availability of Universal Grammar in second language acquisition. The Failed Functional Features Hypothesis. Second Language Research 13: 187-226.

Hawkins, R. \& Hattori, H. 2006. Interpretation of English multiple wh-questions by Japanese speakers: A missing uninterpretable feature account. Second Language Research 22(3): 269-301.

Hawkins, R., Casillas, G., Hattori, H., Hawthorne, J., Husted, R., Lozano, C., Okamoto, A., Thomas, E. \& Yamada, K. 2008. The semantic effects of verb raising and its consequences in 
second language grammars. In The role of features in second language acquisition, J. Liceras, H. Zobl \& H. Goodluck (eds), 328-351. New York NY: LEA.

Hyams, N. 1992. The genesis of clausal structure. In The acquisition of verb placement, J. M. Meisel (ed.), 371-400. Dordrecht: Kluwer.

Iatridou, S. 1991. About AgrP. Linguistic Inquiry 21: 551-577.

Kayne, R. 1994. The antisymmetry of syntax. Cambridge MA: The MIT Press.

Laenzlinger, C. 1998. Comparative studies in word order variation. Amsterdam: John Benjamins.

Poeppel, D. \& Wexler, K. 1993. The full competence hypothesis of clause structure in early German. Language 69: 1-33.

Pollock, J.-Y. 1989. Verb movement, Universal Grammar and the structure of IP. Linguistic Inquiry 20: 365-424.

Prévost, P. \& White, L. 2000a. Accounting for morphological variation in L2 acquisition: Truncation or missing inflection? In The Acquisition of Syntax, M.-A. Friedemann \& L. Rizzi (eds.), 202-235. London: Longman.

Prévost, P. \& White, L. 2000b. Finiteness and variability in SLA: More evidence for missing surface inflection. In Proceedings of the 23rdh annual Boston University Conference on Language Development, A. Greenhill, H. Littlefield \& C. Tano (eds.), 439-450. Somerville MA: Cascadilla Press.

Prévost, P. \& White, L. 2000c. Missing surface inflection or impairment in second language acquisition? Evidence from tense and agreement. Second Language Research 16: 103-134.

Rizzi, L. 1993/4. Some notes on linguistic theory and language development: The case of Root Infinitives. Language Acquisition 3: 371-393.

Sayehli, S. 2001. Transfer and Syntax. A study on the acquisition of German word order by Swedish speakers. MA Thesis, University of Lund.

Schwartz, B. D. 1996. On two hypotheses of 'transfer' in L2A: Minimal trees and absolute L1 influence. In The generative study of second language acquisition, S. G. Flynn, G. Martohardjono \& W. O’Neil (eds.), 17-34. Hillsdale NJ: Lawrence Erlbaum.

Schwartz, B. D. \& Sprouse, R. A. 1996. L2 cognitive states and the full transfer/full access model. Second Language Research 12: 40-77.

Speas, M. 2001. Constraints on null pronouns. In Optimality-Theoretic Syntax, G. Legendre, J. Grimshaw \& S. Vikner (eds.), 393-425. Cambridge MA: The MIT Press.

Tiphine, U. 1983. The acquisition of English statements and interrogatives by French-speaking children. PhD dissertation, University of Kiel.

Tsimpli, I.-M. \& Dimitrakopoulou, M. 2007. The interpretability hypothesis: Evidence from whinterrogatives in L2 acquisition. Second Language Research 23(2): 215-242.

Vainikka, A. 2007. Adverb movement in organic syntax. Ms. (submitted for publication in Syn$\operatorname{tax}$ ).

Vainikka, A. \& Levy, Y. 1999. Empty subjects in Hebrew and Finnish. Natural Language and Linguistic Theory 17: 613-671.

Vainikka, A. \& Young-Scholten, M. 1994. Direct access to X'-theory: Evidence from Korean and Turkish adults learning German. In Language acquisition studies in generative grammar, T. Hoekstra \& B.D. Schwartz (eds.), 265-316. Amsterdam: John Benjamins.

Vainikka, A. \& Young-Scholten, M. 1996a. Gradual development of L2 phrase structure. Second Language Research 12: 7-39.

Vainikka, A. \& Young-Scholten, M. 1996b. The early stages in adult L2 syntax: Additional evidence from Romance speakers. Second Language Research 12: 140-176. 
Vainikka, A. \& Young-Scholten, M. 1998. Morphosyntactic triggers in adult SLA. In Morphology and its interfaces, M-L. Beck (ed), 89-113. Amsterdam: John Benjamins.

Vainikka, A. \& Young-Scholten, M. 2002. Restructuring the CP in L2 German. In Proceedings of the 26th BUCLD, B. Skarabela, S. Fish \& A. H.-J. Do (eds.), 712-722. Somerville MA: Cascadilla Press.

Vainikka, A. \& Young-Scholten, M. 2005. The roots of syntax and how they grow. Organic grammar, the basic variety and processability theory. In Paths of development in L1 and L2 acquisition, S. Unsworth, A. Sorace, T. Parodi \& M. Young-Scholten (eds.), 77-106. Amsterdam: John Benjamins.

Vainikka, A. \& Young-Scholten, M. 2007. Minimalism vs. organic syntax. In Clausal and phrasal architecture: Syntactic derivation and interpretation. Papers in honour of Joseph Emonds, S. Karimi, V. Samiian \& W. Wilkins (eds.) Amsterdam: John Benjamins.

Weissenborn, J. 1990. Functional categories and verb movement: The acquisition of German syntax reconsidered. Linguistische Berichte 3: 190-224 (Special Issue).

Wexler, K. 1994. Optional infinitives, head movement and the economy of derivations in child grammar. In Verb movement, D. Lightfoot \& N. Hornstein (eds.), 305-350. Cambridge: CUP.

White, L. 1991a. Adverb placement in second language acquisition: Some effects of positive and negative evidence in the classroom. Second Language Research 7: 133-160.

White, L. 1991b.: The verb-movement parameter in second language acquisition. Language Acquisition 1: 337-360.

White, L. 1992. Long and short verb movement in second language acquisition. Canadian Journal of Linguistics 37: 273-286. 